\title{
On the New Rural Construction Strategies Under the Background of Low-Carbon Economy
}

\author{
$\mathrm{ZHI} \mathrm{LI}$ \\ College of Business Administration, Kaifeng University, Dongjing Road, Kaifeng City, China \\ Izhaaron@aliyun.com
}

Keywords: low-carbon economy, the new rural construction, strategy

Abstract. How to speed up the construction of modern agriculture in China, to further enhance the income of farmers, to improve the ecological environment in rural areas, they have become the fundamental problems in the process of building a new countryside. Today, the low-carbon economy provides a new path for the development of China's implementation of the new rural construction, through the introduction of the low-carbon economy in the new rural construction mode, not only guarantee the implementation of the new rural construction, but also avoid the old way of rural, which is "pollution first, treatment later", the low-carbon economy is the reasonable choice of promote Chinese rural economic and social development. This paper provides an overview of the low-carbon economy, analysis the urgency of developing the low-carbon economy with the background of the New Rural Construction, and proposes strategies of how to strengthen the new rural construction with the background of the low-carbon economy.

\section{Introduction}

In view of the continued increase in world population and economic scales, people known more about the environment problems caused by energy utilization. And the most prominent is the global warming, sea level rising, and natural disasters, these extreme weather changes give significant challenges to human survival and development. Therefore, the low-carbon economy that based on reduces energy consumption, green energy research and development will become the future trend. The core of the low-carbon economy is to change the concept of human survival and development, that is can't be avoid issue during the process of socio-economic development. At present, the new rural construction as one of the major tasks in China's modernization process, it is the fundamental measure of improving farmers' lives, narrowing the gap between urban and rural areas and achieving common prosperity. Researching on the basis of economic models, implementation of the new rural construction, and also after the success of the industrial economy, it is the feedback and return of industrial to agriculture. The manifestation of this behavior in the real world is the Government increases the funding of agriculture, so that the vast number of rural people will feel the charm of industrial civilization. Therefor, advancing the new rural construction guided by the low-carbon economy.

\section{Overview of the low-carbon economy}

Low-carbon economy, means on the basis of does not affect the local economy, constantly reducing the consumption of resources and energy by institutional and technological innovation, thereby reducing emissions of greenhouse gases and pollutants maximally, and promoting long-term economic and social sustainable development. The core of low-carbon economy is the goal of a new mode of economic development that based on low energy consumption, low pollution and low emissions. The essence of the low-carbon economy lies the clean and efficient use of energy, its goal is to achieve energy conservation and emission reduction, climate warming, which is also the only way must be passed from industrial civilization to ecological civilization of human society. During the new rural construction of China, analysis the internal mechanism of the new rural construction through the low-carbon economy, transform the mode of agricultural productive and development method as much 
as possible; reduce carbon emissions and energy consumption in agriculture, and committed to the development of clean, efficient and recycling low carbon agriculture.

\section{The urgency of developing the low-carbon economy with the background of the new rural construction}

Low-carbon economy is one of the new economic models based on the idea of sustainable development, regardless of nations, cities or rural areas; the low-carbon economy is one of the inevitable choices of the ideal development model. Therefore, the new rural construction with low-carbon economy has become necessary for socio-economic development; it is of great significance. (1) The rural area is the main position of advocates the concept of low-carbon. (2) Urgent demand of economic and social development in rural areas. (3) To contribute to the achievement of social justice. Create the new socialist rural with the low-carbon economy, directly related to human development, social equity and justice. (4) The new rural construction with low-carbon economy has the direct effect to build green and premium environment, and be able to promote harmonious development between human and nature. The new rural construction with low-carbon economy, able to reflect people-oriented scientific development concept, thus to create a better economic and ecological environment for rural people, improve their living environments, maintain ecological balance, achieve green development, sustainable development, the harmonious development between human and nature. (5) The new rural construction with low-carbon economy helps release the contradictions between agricultural development and energy shortages. Agriculture as the foundation of the national economy, the issue of feeding 1.4 billion people can be said a monster problem. So that to ensure food security, and also ensure the agriculture to achieve sustainable development, which will certainly result the contradictions between agriculture, development and limited consumption resources. If the traditional production mode still were used, it is difficult to resolve the contradiction between development and lack of resources. To resolve this contradiction, it is necessary to transform existing agricultural production mode, and blaze a path of low-carbon development, enhance the efficiency of resource usage, promoting the development and improve of China's agriculture, thereby strengthening the basic position of agriculture in China. (6) The new rural construction with low-carbon economy helps promote the transform of rural people's lifestyle and consumption patterns. Actively promote low-carbon economy development and advocate people to live a low carbon life, help people enhance awareness of low-carbon life, change the vices that are lack of politeness in rural areas, thus contributing to form civilized consumptions in rural China.

\section{Relevant strategies of the new rural construction with low-carbon economy}

\section{( 1 ) Adjusting measures to local conditions, balance the protection and development.}

During the process of the new rural construction, highly priority to the rural cultural construction and protection, maintain the cultural diversity. Nobility and returning to nature is the development trend of global industrial civilization. What used to be considered backward and national is rare and valuable in the eyes of the contemporary people. So during the new rural construction, particularly in the minority areas, should conduct a more comprehensive survey of rural culture, so as to understand and grasp the overall situation. Villages with rich cultural characteristics should be classified, and targeted implementation the protection programme, put it in the local planning of the new rural construction, synchronized between protect the rural culture heritage effectively and the development of the rural economy coordination, and avoid losses due to one-sided development, construct the ecological rural, become carbon neutral, and strive to achieve zero emissions, while reducing carbon sources to develop carbon sequestration project, that is carbon offsets to neutralize carbon emissions so as to realize zero emissions. Increase the green coverage rate, establishment the three-dimensional multi-level Green system, increase the area of ecological environment. 
( 2 ) Exploring the mode of low-carbon agriculture, promoting energy conservation and emission reduction.

The new rural construction under the background of low-carbon economy is facing a multitude of problems which include the pollution is getting worse in the area of agricultural production, serious emission by township enterprises, lack energy structural diversity. Meanwhile there are a lot of factors that affect the development of the low-carbon economy in the rural area of China: low level of agricultural modernization, propaganda strength to environmental protection is not enough by government, less investments for environmental protection in the rural areas, lack of environmental protection laws and regulations. Therefore, it is important to solve the problems happen during the process of the new rural construction with the low-carbon economy through development and productive proactively.

a. Strengthening the construction of eco-agriculture and circular agriculture, realize the low-carbon economy in agricultural production.

Essences of low carbon agriculture are low consumption, low pollution, and low emissions. It is necessary to endeavor to do the following: first, to fully adjust the agricultural structure, not only to eliminate outdated technology in agricultural production, but also prolongs the agricultural industrial chain. Second is through technological innovation and improve the traditional technology, application of new agricultural techniques, develop the implementation of carbon storage and recycle by the agricultural ecological system. The third one is recycling the various types of waste during the implementation of agricultural production. In developing the low-carbon economy especially the green agriculture, should strive to achieve the recovery and recycle of various types of agricultural waste resources. Only by this way can save the usage of energy in agricultural development, improve the effectiveness of resource usage; promote the large-scale development of China's agricultural production.

b. Using the science and technology innovation of agricultural, implement the innovation and development of agricultural industry.

Innovation and development of China's agricultural industry must transform from energy-intensive economy to a low-carbon economy, therefore, it is necessary that develop low carbon agriculture-related technologies actively. This mainly refer to minimum the number of greenhouse gas emissions in process of agricultural production and management, but maximum the social benefits. In General, low-carbon agricultural technology has the following three characteristics: first, it has the low energy consumption, low pollution, and low emission so called "three low" features. Second is the feature of saving, try to economize resources consumption, thus reducing the inputs of human, financial and material resources. Finally is the security feature, using a variety of practical measures to minimized the potentially polluting activities during the process of agricultural production. In the new rural construction, only agricultural technologies with these characteristics have strong vitality, only actively promoting resource-saving and eco-friendly agricultural technology, improving energy, efficiency, and clean energy in order to better meet the requirements the modern agriculture construction, which promotes the development of new agricultural production in China.

\section{( 3 ) Actively creating the low-carbon community.}

In the construction of new homes in rural areas, should put a new premium on building low carbon housing, to fully consider people's health on the basis of more rational usage of energy-saving technologies and materials, promote the application of renewable energy and emission reduction technologies and new products, accelerate technical energy-saving. Comprehensive the water saving, energy saving, solar and other energy-saving technologies. The highly and applicable technology should be adopted by low-carbon buildings to control and reduce energy consumption, it is extremely ecological that Chinese traditional architecture are able to consciously make full use of wind and solar power. The low-carbon buildings should take advantage of solar and wind energy and other renewable energies; pursuing trendy is not necessary in the process of the new rural construction. The rural areas should keep the power-saving methods of the traditional architectures and also make the 
scientific planning for rural communities, such as the size and location of biogas, intensive housing structure, etc.

Establishing the perfect mechanism to run the low-carbon economy, and innovation management methods. Formulate and implement the short, medium and long-term plans and goals for energy conservation and emission reduction, realization the control and management for the whole process of the new rural construction under the background of low-carbon economy, make it quantitative, operable, and be available for examination, evaluation and management. Increase the supervision; build a professional management team, and a long-term mechanism with incentive and restraint.

(4) Creating spiritual and cultural atmosphere for the low-carbon in the rural areas, strengthen the awareness of legal, low-carbon and environmental protection.

China's education sector should play an exemplary role, consciously implemented environmental education activities in schools so that and help rural children to build environmental awareness like urban kids, give fully play the oriented function of school cultural spirit.

Township Governments should enhance the propaganda of environmental protection for peasants, raising their awareness for waste classification treatment. And also through television, radio, newspapers and other media resources, actively promote knowledge of ecological environmental protection in rural areas, bring the idea of low-carbon the their daily life.

Efforts to improve the existing legal system of environmental protection in rural areas to adapt to the new challenges of pollution prevention and control. On this basis, should also implementation the environmental policies and regulations more strictly, making full use of laws and regulations to protect the rural environment from various types of pollution.

\section{Conclusion}

To sum up, in the process of the new rural construction with Chinese Socialist characteristics, it is important to realize the healthy and stable development of the rural economy by actively promoting the low-carbon economy. This requires us correct understanding the positive effects in the process of the low-carbon economy; delve the path selection for low carbon development in the process of the new rural construction. This will not only deliver our commitment of take the road of sustainable development for the world, but also improve the living environment, in order to achieve the sustainable development of human and nature. So with that being said, the new rural construction under the background of low-carbon economy has the great significance for coordination of China's economic and social development.

\section{References}

[1] Wu Yuan, the Development of New Rural Construction on the Basis of Low-Carbon Economy, Modern Economic Information, 2012(3), p337.

[2] Yang YUjuan, Fang Xue. How the Low-Carbon Economy Enhance the New Rural Construction in the City of Jiamusi, Market Modernization, 2013(4), p150-151.

[3] Chen Xiaochun, Tang Yijun. Research on the Low-Carbon Rural Construction in China, Social Sciences in Yunnan, 2010(2), p107-112.

[4] TAO Ping. Development of Circular Economy of Rural Sports Tourism: Besed on the Perspective of Low Carbon Ecoligical, Journal of Dhenyang Sport University, 2014(2), p64-67.

[5] Gao Zhichun,LI Liang. The Low Carbon Economy Research both at Home and Abroad, Environment and Development, 2014(4), p1-2.

[6] Bi Hong. New Rural Construction based on Low Carbon Economy, Money China, 2014(2), p36-37. 